\title{
A criança com autismo na brinquedoteca: percursos de interação e linguagem
}

\author{
Ivone Martins Oliveira* \\ Sonia Lopes Victor **
}

\section{Resumo}

Este artigo tem como objetivo apresentar os resultados de análises de um estudo de caso sobre modos de interação estabelecidos entre uma criança com autismo e os adultos em uma brinquedoteca. Apoia-se nos estudos de Lev Semenovitch Vigotski e Mikhail Bakhtin, que abordam o papel da linguagem na constituição da consciência e enfocam os processos de significação que subjazem aos processos interativos. A pesquisa de campo foi realizada em uma brinquedoteca universitária que atendia a crianças com e sem deficiência, uma vez por semana, durante quatro meses. Contou, para isso, com a participação de graduandos do Curso de Educação Física, docentes da universidade e uma psicóloga. Os dados foram registrados por meio de filmagens, gravações em áudio e anotaçôes em diário de campo. Considerando os objetivos do estudo, enfocaram-se os processos interativos estabelecidos entre um menino com autismo de dois anos e oito meses, que não apresenta uma linguagem articulada, e duas pesquisadoras. As análises indicaram que a criança interage com adultos, utilizando recursos não verbais, por vezes sutis, em um curto intervalo de tempo, os quais são significados por eles, permitindo manter a interação e enriquecer as possibilidades de interlocução. O estudo conclui que, mesmo não tendo uma fala articulada, essa criança se constitui como um sujeito em condiçôes de se posicionar de forma ativa e responsiva nos processos interativos estabelecidos com as pesquisadoras, nos quais o papel do adulto é fundamental, de forma a criar condiçóes favoráveis à participação da criança no jogo dialógico.

Palavras-chave: Autismo; Interação; Linguagem.

\footnotetext{
* Doutora em Educação pela Universidade Estadual de Campinas, Campinas, São Paulo, Brasil.

** Doutora em Educação pela Universidade de São Paulo (PDJ), São Paulo, São Paulo, Brasil.
} 


\section{The child with autism in the playroom: interaction paths and language}

\section{Abstract}

This paper aims at presenting the results of the study case analyses about interaction modes established between a child with autism and adults in a playroom. It supported by the studies of Lev Semenovitch Vygotsky and Mikhail Bakhtin, who discuss the role of the language in the conscience constitution and emphasize the significance processes that underlie the interactive processes. The field research was carried out inside a university playroom that assisted disabled and non-disabled children once a week, for four months. To do so, it counted with the participation of Physical Education Course graduates, university students and a Psychologist. Data was registered through shootings, audio recordings and field diary records. Taking the study goal into consideration, it was focused on the interactive processes established between a two-year and eight months old autistic boy who does not present an articulated language, and two Researchers. The analyses indicated that the child interacts with adults, using non-verbal resources, subtle at times, and occurring at a short period of time, which are meant by them, allowing keeping the interaction and enriching the interlocution possibilities. The work concludes that, even without an articulated speech, that child is constituted as a subject who is able to be positioned in an active and responsive way in the interactive processes established with the Researchers. In this process, the adult role is fundamental in order to create favorable conditions to the child participation in the dialogic game.

Keywords: Autism; Interaction; Language.

\section{El niño con autismo en la ludoteca: recorridos de comunicación y lenguaje}

\section{Resumen}

Este artículo tiene como objetivo presentar los resultados de un estudio de caso sobre los modos de comunicación establecidos entre un niño con autismo y los adultos en una ludoteca. Fundamentado en los estudios de Lev Semenovitch Vigotski y Mikhail Bakhtin, que abordan el papel del lenguaje en la constitución de la consciencia y enfocan los procesos de significación que subyacen a los procesos comunicativos. La investigación de campo fue realizada en una ludoteca universitaria que atendía a nińos con y sin discapacidad, una vez por semana, durante cuatro meses; contando para eso con la participación de estudiantes del Curso de Educación Física, profesores de la universidad y una psicóloga. Los datos fueron registrados por medio de videograbaciones, grabaciones de voz y anotaciones en el diario de campo. Considerando los objetivos del estudio, se analizó los procesos comunicativos establecidos entre un niño con autismo de dos años y ocho meses, que no presenta un lenguaje articulado, 
y dos investigadoras. Los análisis indicaron que el nińo se comunica con los adultos, utilizando recursos no verbales, algunas veces sutiles e ocurriendo en un intervalo de corto tiempo, los cuales son significados por ellos, lo que permite mantener la comunicación y enriquecer las posibilidades de interlocución. El estudio concluye que, aunque no tenga un habla articulada, ese niño se constituye como un sujeto en condiciones de posicionarse de forma activa y responsiva en los procesos comunicativos establecidos con las investigadoras. En ese proceso, el papel del adulto es fundamental para crear condiciones favorables para la participación del niño en el juego dialógico.

Palabras-clave: Autismo; Comunicación; Lenguaje.

\section{Introdução}

Entre os estudos sobre autismo na área educacional, são recorrentes as referências aos desafios enfrentados pelos profissionais quanto à interação e à comunicação com crianças com diagnóstico de autismo, considerando as peculiaridades de seu desenvolvimento (LEMOS; SALOMÃO; AGRIPINO-RAMOS, 2014; SAMPAIO; MIURA, 2015; SCHMIDT et al., 2016).

Reportando-se às angústias de alguns docentes em relação às possibilidades de comunicaçáo com crianças com autismo, Santos e Santos (2012) destacam que, acostumados com padróes de interação e comunicação centrados na linguagem verbal e na utilização de determinados recursos comunicativos, como expressóes faciais e contato pelo olhar constante e longo, esses profissionais habitualmente têm dificuldades de interagir com elas quando as situaçôes de interação não seguem esse padrão. Com frequência, as respostas apresentadas pelas crianças com autismo, em frente às tentativas de contato por parte de professores, são interpretadas por eles como indiferença, ausência de comunicação ou incapacidade para o contato, gerando frustração e desânimo. Das expectativas frustradas e do baixo investimento pelos docentes em situaçóes favorecedoras de avanços no seu aprendizado, resulta a impossibilidade de essas crianças desenvolverem o máximo de suas potencialidades no processo de escolarização.

Diante disso, um aspecto reiteradamente mencionado por estudos sobre a temática, refere-se à necessidade de se investir na formação de profissionais da educação que trabalham com essas crianças. Para dar suporte a essa formação, é importante que se realizem estudos sobre as formas de interação e de interlocução com a criança com autismo em ambientes coletivos. Como parte desse panorama, este estudo visa a analisar os modos de interação e de interlocução estabelecidos entre uma criança com diagnóstico de autismo e os adultos durante atividades lúdicas em uma brinquedoteca.

\section{Autismo, interação e linguagem}

O autismo é uma síndrome cujas principais características definidas nos manuais diagnósticos1 têm sido os comprometimentos na interação social, na linguagem, na comunicação e na imaginação, os movimentos repetitivos e os interesses restritos. 
No que tange especificamente à linguagem e comunicação, Siegel (2008) destaca como aspectos mais comuns: o hábito de conduzir o outro pela máo, quando a criança deseja algo que não consegue obter sozinha, em substituição ao gesto de apontar; contato ocular muito breve ou com características de um olhar ausente; manutenção de um distanciamento físico maior dos outros - quando próximas, preferem sentar ao lado e não de frente para eles; manifestaçóes de emoçóes restritas, oscilando entre expressóes de excitação e bem-estar ou de mal-estar; ritmo de desenvolvimento da linguagem lento; vocabulário reduzido e ecolalia. Algumas crianças podem não falar, mas isso não significa uma total falta de compreensão da linguagem verbal ou que elas não sejam capazes de se comunicar com os outros.

De modo geral, a compreensão que os profissionais da educação têm sobre o autismo está perpassada pelo olhar predominante da área médica, o qual se reflete na própria avaliação diagnóstica.

Conforme ressalta Vasques (2015), no diagnóstico, ressalta-se uma perspectiva biológica e organicista de olhar para o sujeito que busca conhecê-lo tomando como referência sistemas de classificação. Conhecer, nesse caso, restringe-se a situar o sujeito em um determinado quadro nosográfico e a seguir por "[...] um caminho já naturalizado, traçado, percorrido e definido pelas características internas ou externas da criança” (VASQUES, 2015, p. 56). Enfim, um caminho que pouco possibilita compreender quem é a criança com autismo, como é afetada pelos acontecimentos que a rodeiam e em que bases devem estar assentadas as práticas educativas orientadas para ela na escola.

Em meio a esse contexto, no espaço escolar, frequentemente, delineiam-se questionamentos a respeito do potencial dessas crianças para a aprendizagem, acompanhados de práticas pedagógicas centradas, sobretudo, no desenvolvimento de habilidades básicas e de socialização (FAVORETTO; LAMÔNICA, 2014; VASQUES; BAPTISTA, 2014; SCHMIDT et al., 2016). Diante das peculiaridades dos modos de interação dessas crianças, de maneira geral, elas permanecem isoladas no ambiente escolar, as possibilidades de partilha de experiências com os outros são reduzidas e as situaçôes de interlocução empobrecidas.

Por outro lado, apoiando-nos nos postulados da Perspectiva Histórico-Cultural (VIGOTSKI, 1983, 1997), entendemos que avanços nas interaçôes sociais e no desenvolvimento da linguagem em crianças com autismo ocorrerão na medida em que o contexto em que vivem lhes possibilitar ricas experiências de interação e de interlocução.

Para Vigotski (1983, 1979), o psiquismo humano se constitui a partir de um processo em que funçóes elementares se alteram por meio da criação de novas conexôes, de novas formas de articulaçáo entre elas. Nesse percurso, a linguagem ocupa um lugar de destaque, na medida em que começa a funcionar como um elemento mediador na relação entre a criança e o mundo e consigo própria. A linguagem possibilita um modo particular de organizaçáo do psiquismo humano e de regulaçáo da própria conduta, a partir da internalização das palavras dos outros. Retomando Pierre 
Janet, Vigotski (2000, p. 25) afirma que, como um signo, a palavra “[...] é sempre comando. Portanto o meio fundamental de domínio"; inicialmente é uma "ordem" dos outros para a criança e depois uma "ordem" dela para si própria. Ao tratar do desenvolvimento da linguagem na criança, Vigotski (1979) articula-a com o desenvolvimento do pensamento e enfoca o pensamento verbal, de onde se destacam, para ele, significados e sentidos, elementos centrais na constituição das funçóes psíquicas superiores.

A apropriação e o uso de signos possibilitam à criança inserir-se em um grupo social, apropriando-se, também, de sua cultura, num processo de conversão de relaçóes sociais em processos psíquicos. Assim, ressalta Pino (2000, p. 55) que o que é apropriado pela criança "[...] não é o gesto, como materialidade de movimento, mas a sua significação. É a significaçấo que tem o poder de converter o fato natural em fato cultural e, dessa maneira, permite a passagem do plano social para o pessoal".

$\mathrm{O}$ uso de signos implica um ambiente social e a partilha de signos pelos sujeitos envolvidos na interação (BAKHTIN, 1986; 1992). A emergência da significação demanda o espaço coletivo, a interação verbal estabelecida como parte de um universo social e histórico mais amplo, que lhe oferece os contornos e constitui os interlocutores.

A linguagem é compreendida, neste trabalho, como prática social, que se desenvolve na interação entre homens e dos homens com a natureza. Produção simbólica, a linguagem se configura como parte da produção social mais ampla da sociedade, constituindo e ao mesmo tempo sendo constituída pelas forças em jogo num determinado contexto histórico e político.

Dessa concepção de linguagem decorre uma compreensão do signo em uma perspectiva mais ampla, que engloba, para além da palavra, outros componentes que também podem se constituir em signo ideológico, a partir de sua existência material “[...] seja como som, como massa física, como cor, como movimento do corpo ou outra coisa qualquer" (BAKHTIN, 1986, p. 33). É a possibilidade da significação, na relação entre os interlocutores, que define um dado fenômeno como signo. Dessa forma, é na relação com o outro, nas possibilidades de construção de sentidos que surgem nessa relação, que a criança com autismo vai se constituindo como um interlocutor e suas palavras, seus movimentos e manifestaçóes expressivas podem se configurar como signo.

Nessa perspectiva, não verbalizar não significa necessariamente não produzir sentido na relação com o outro, pois outros elementos podem tomar o lugar da palavra nos processos interativos. Assim, Bakhtin (1986) nos mostra que, na relação com a criança com autismo que não verbaliza, o adulto tem um papel fundamental de forma a inserir sua produção não verbal no universo de uma "refração ideológica verbal", possibilitando a produção de sentidos. 


\section{Metodologia}

Este trabalho é um recorte de uma pesquisa de estudo de caso, que tem como objetivo analisar os modos de interação e de interlocução entre crianças com autismo e os adultos e outras crianças, durante a realização de atividades lúdicas numa brinquedoteca.

A investigação foi realizada em uma brinquedoteca universitária, vinculada a um Centro de Educação Física e Desportos de uma instituição de ensino superior. Nessa brinquedoteca, são desenvolvidos projetos de pesquisa e de extensão que se orientam por uma perspectiva inclusiva. Em conformidade com documentos oficiais que reafirmam os direitos da pessoa com deficiência à educação e ao desenvolvimento do máximo de suas potencialidades (BRASIL, 2008, 2015) e, sobretudo, os direitos da criança à educação em conjunto com as demais crianças, considerando suas especificidades e modos de conhecer o mundo por meio da brincadeira (BRASIL, 2006) - os projetos desenvolvidos na brinquedoteca orientam-se para a promoção de açôes lúdicas, que visem à interação entre crianças com e sem deficiência e dessas crianças com os adultos, bem como ao desenvolvimento do brincar.

No segundo semestre de 2015, participaram das atividades desenvolvidas na brinquedoteca 22 crianças sem deficiência de um Centro de Educação Infantil, cinco crianças com autismo e uma com síndrome de Down, de diferentes bairros do município. Todas elas tinham idades entre dois anos e meio e seis anos. Para desenvolver as atividades, a intervenção com as crianças contou com a participação de 16 estagiários do Curso de Educação Física, uma psicóloga do Centro de Atenção Psicossocial Infanto-Juvenil e os coordenadores do projeto.

As sessōes lúdicas foram observadas durante quatro meses, uma vez por semana, com duração de 60 minutos cada uma. $O$ registro do trabalho desenvolvido com as crianças foi feito por meio de filmagens, gravações em áudio, fotografias, anotações em diário de campo. Foram realizadas, ainda, entrevistas com os pais das crianças com autismo.

As primeiras análises do material coletado apontaram aproximaçóes e divergências nos modos de interação e de interlocução entre as crianças com autismo, os adultos e as demais crianças. Os meninos mais velhos (Hélio, três anos e quatro meses, e Gerson, quatro anos e dez meses) mostravam-se mais disponíveis para interagir com os outros; utilizavam a linguagem verbal, embora com baixa frequência e vocabulário restrito; e manifestavam mais interesse por brinquedos e materiais lúdicos do que as crianças mais novas (Augusto e Celso, três anos, e Murilo com dois anos e oito meses).

Para este trabalho, optamos por enfocar Murilo, um menino com diagnóstico de autismo, pelos desafios que trouxe durante as intervençóes no desenvolvimento de estratégias de interação com ele e pela sua participação nas atividades lúdicas coletivas realizadas na brinquedoteca. As análises foram desenvolvidas de maneira a compreender os processos interativos estabelecidos entre essa criança, que pouco verbalizava, e dois adultos com os quais ela mais interagiu na brinquedoteca. 


\section{Resultados e discussão}

No início da pesquisa de campo, Murilo frequentava um centro de educação infantil privado, além de ser atendido por terapeuta ocupacional, fonoaudióloga e psicóloga. Tomava uma medicação fitoterápica, segundo o pai, para ficar mais calmo. Por volta de um ano e meio, teve de fazer uma cirurgia do coração e ficou 11 dias internado em uma unidade de terapia intensiva.

Murilo costumava chegar à brinquedoteca no colo do pai ou junto com a mãe e o irmão de aproximadamente seis meses. Por algumas vezes, o pai se dispôs a participar das atividades desenvolvidas com o filho.

De modo geral, o menino náo tomava a iniciativa de interagir com outros adultos e crianças, permanecendo a maior parte do tempo circulando pela brinquedoteca, seguindo um percurso bem marcado: ia para o canto onde há uma pequena escada com corrimáo, onde ficava algum tempo; corria em círculos no centro da brinquedoteca, balançando os braços e, por vezes, balançando a cabeça; ia até o outro lado da sala onde há um painel de vidro com algumas figuras coladas, voltava ao centro da sala, olhava um ventilador, virava-se de costas; caminhava em direção à parede oposta e ficava olhando para o outro ventilador; aproximava-se de uma bicicleta e rodava o pneu durante alguns segundos. Repetia novamente o trajeto. Esse percurso era interrompido quando um adulto conseguia orientar sua atenção para outros objetos ou atividades. Algumas vezes observamos a emissão de sons vocálicos incompreensíveis em tom baixo.

$\mathrm{Na}$ brinquedoteca, notamos que o interesse de Murilo por objetos restringia-se, por exemplo, ao pneu de uma bicicleta, a um painel de vidro com figuras de árvores e pássaros afixadas, bolas coloridas e bambolê, além do ventilador.

O interesse de crianças com autismo por objetos pouco comuns e o estabelecimento de rotinas rígidas ou necessidade de "imutabilidade" são apontados por estudos sobre a temática como aspectos frequentes no comportamento dessas crianças (SIEGEL, 2008). Uma hipótese para essa insistência na imutabilidade de objetos, açóes e percursos diz respeito à segurança que a previsibilidade dessas rotinas pode trazer para a criança.

No que tange às relaçôes, observamos pouquíssimos eventos em que Murilo tomou a iniciativa de interagir com os adultos. De modo geral, essas iniciativas visavam a solicitar a ajuda para subir na cama elástica para pular, ser pego pelo adulto para que ele o rodasse ou levantasse no ar e também para proteger-se de um objeto que lhe causava medo.

$\mathrm{Na}$ maior parte do tempo, é o adulto que toma a iniciativa de interaçáo, utilizando-se de diferentes estratégias para obter a atenção do menino: chamar seu nome de forma melodiosa, falar com ele, acompanhá-lo no trajeto pela brinquedoteca, apresentar-lhe um brinquedo, cantar cantigas de roda para ele. Quando o adulto consegue chamar sua atenção, Murilo geralmente responde aproximando-se ou olhando rapidamente para ele. Em frente a uma atividade que lhe provoca bem-estar, algumas vezes ele sorri, mantém breve contato visual com o outro e verbaliza uma sequência de sons vocálicos. 


\section{Palavra, olhar, gestos, manifestações expressivas e produção de sentidos na interação}

Analisando o material coletado, constatamos que, diante de situaçôes cuidadosamente conduzidas pelos adultos, Murilo interage com eles, utilizando recursos não verbais. Na medida em que esses recursos são interpretados pelos outros e passam a agir em relação ao menino conforme essa interpretação, ampliam-se as possibilidades de manutenção da interação, de produção de sentidos na relação e de constituição de Murilo como um interlocutor no jogo enunciativo (BAKHTIN, 1986).

Durante a pesquisa de campo, observamos particularmente três encontros em que se estabeleceu uma enriquecida interação entre Murilo e um adulto, ainda que não fosse perpassada pela linguagem verbal. Nesses encontros, o olhar ocupa um lugar de destaque: constitui-se em indício de que a criança está atenta aos estímulos presentes à sua volta, funciona como uma resposta ao adulto no processo interativo e o conduz na manutenção da interação. Considerando os limites deste texto, abordaremos dois desses eventos.

No dia 15 de outubro, as atividades lúdicas com as crianças ocorreram num jardim próximo à brinquedoteca. Quando Murilo chegou, essas atividades já haviam começado. Ele não se sentiu confortável no local e chorou, não aceitando a aproximação e contato com os adultos. Então foi levado à brinquedoteca onde, aos poucos, foi se acalmando. Durante algum tempo, ele se envolveu nas açôes repetitivas que costumava desenvolver. Nesse percurso, a psicóloga Rafaela tentou por várias vezes e utilizando diferentes recursos chamar a atenção do menino, mas sem muito sucesso. Então, ela decidiu pegar um violãozinho de brinquedo e começou a tocar e cantar cantigas infantis. A partir desse momento, foi possível notar algumas alteraçôes no comportamento de Murilo que orientaram Rafaela na condução do processo interativo:

No centro da brinquedoteca, Rafaela toca e canta enquanto Murilo corre em círculos. Ela pergunta a ele se quer ouvir a música "Pintinho Amarelinho". Ela começa a cantar, Murilo diminui o ritmo da corrida e olha rapidamente para ela. Quando ela canta "Com seus pezinhos ele cisca o chão, ele bate as asas", ela faz um movimento com os pés de ciscar o chão e balança os braços, como se fossem asas, então ele para e olha rapidamente para ela, caminha para perto de Rafaela e faz um movimento em direção à mão dela, que retribui o movimento tocando a máo dele e continua cantando. Murilo anda pela brinquedoteca e roda o pneu da bicicleta. Rafaela se aproxima dele e pergunta de qual outra música ele gosta. Quando Rafaela começa a tocar a cantiga "Caranguejo peixe é", ele se levanta e começa a correr em círculo e balançar os braços e a cabeça enquanto verbaliza "Ohohoh" em tom melódico. Rafaela canta "Palma, palma, palma, pé, pé, pé, roda, roda, roda caranguejo peixe é" e roda em volta de si mesma, enquanto Murilo continua correndo em círculos. Quando Rafaela canta esse trecho pela segunda vez, bate palma, bate o pé no chão e roda em torno de si mesma, o menino vai diminuindo a velocidade da corrida em círculo e começa a andar, olha rapidamente para ela e balança 


\begin{abstract}
o tronco e a cabeça e depois volta a correr. Ao cantar o refrão da música pela terceira vez, fazendo os movimentos, Murilo para e olha para ela, começa a andar e quando ela gira em volta de si mesma, ele olha rapidamente para ela de novo. Quando termina a música, em tom melódico, Rafaela diz: “Ei, viva Murilo, viva!”. Nesse momento, ele balança o tronco e a cabeça e roda em torno de si mesmo várias vezes, aparentando euforia.
\end{abstract}

Nesse episódio, notamos que o som do violãozinho e das cantigas infantis, associado a movimentos feitos por Rafaela, sobretudo de girar em torno de si mesma, atraíram a atenção da criança, alterando um pouco seu padrão de movimentos na brinquedoteca. O primeiro aspecto a ser destacado é o movimento rápido de virar-se para Rafaela e olhá-la brevemente enquanto ela cantava e executava alguns movimentos.

A ausência ou escassez de contato ocular tem sido apontada como um dos componentes do quadro autístico (SIEGEL, 2008), o que, muitas vezes, angustia aqueles que atuam com a criança, por não saberem se ela está compreendendo o que ocorre à sua volta. A situação descrita nos permite argumentar que o fato de não olhar não significa necessariamente que a criança está à margem do processo interativo.

Conforme aponta Bosa (2002), estudos produzidos com base em teorias sociocognitivistas tendem a relacionar o não olhar da criança com autismo com a não compreensão da função comunicativa do olhar. Por outro lado, a situação descrita nos permite levantar a hipótese de que a criança olha para o outro também por uma motivação afetiva. Murilo olha na direção de Rafaela, em diferentes momentos, porque parece ter sido afetado pela música e pelos movimentos que ela faz.

No evento transcrito, há fala por parte de Rafaela e emissão de um som vocálico por Murilo. Mesmo náo tendo um retorno verbal da criança na forma de palavras, Rafaela procura interagir com ela tendo a linguagem verbal como mediadora da interação, além dos gestos. Ela pergunta a Murilo sobre as músicas de que ele gosta e ele não responde. Mas, pelos movimentos da criança, ela interpreta que há uma receptividade às cantigas e continua cantando. Embora não se estabeleça um diálogo mediado pela palavra, é a linguagem verbal que perpassa as interpretaçóes e açóes de Rafaela, permitindo-nos considerar, como Bakhtin (1986), que, ainda onde prevalece a interação por meio de signos não verbais, é a palavra, predominantemente, que dá suporte à produçấo de sentidos e orienta o fluxo do diálogo.

Ao final do episódio, encontramos indícios de uma interferência mais explícita da palavra nas açóes de Murilo. Quando Rafaela diz, em tom melodioso: "Ei, viva Murilo, viva!", ele balança o tronco e a cabeça e roda em torno de si mesmo várias vezes, alterando um pouco o padrão que vinha seguindo antes. Nesse momento, entendemos que, de alguma maneira, a criança é afetada pela palavra de uma forma que parece lhe causar bem-estar, e isso se expressa em seus gestos e movimentos.

Apoiando-se na Linguística da Enunciação e tendo como referência Émile Benveniste, Barros (2011) defende uma apropriaçáo da língua pela pessoa com autismo e sua constituição como um sujeito de linguagem, ainda que com características 
peculiares. Segundo a autora, "[...] ao não esboçar aparente reação, repulsar ou ignorar o discurso do interlocutor, o autista emite uma resposta a algo que foi enunciado e se enuncia, posto que reage a algo exterior a ele" (BARROS, 2011, p. 229). Para a autora, a possibilidade de a pessoa com autismo se colocar na linguagem está relacionada com a postura que seu interlocutor tem diante de seus enunciados. No jogo enunciativo, os interlocutores não se constituem um independente do outro, mas no fluxo da própria interlocução.

Ainda que se estabeleçam diferenças entre os postulados que orientam os estudos de Bakhtin $(1986,1992)$ e os de Benveniste (1976), ambos os autores permitem situar a produçáo verbal e náo verbal da criança com autismo no universo da linguagem e reconhecer o papel fundamental do adulto como um interlocutor dessa criança e, ao mesmo tempo, constituí-la como interlocutora. No espaço educacional, esse pressuposto é potente para orientar formas de interação e práticas educativas para essa criança.

Por outro lado, o que sobressai, à primeira vista, na interação entre Rafaela e Murilo, é o diálogo corporal que se estabelece entre os dois: o movimento da psicóloga afeta Murilo, alterando um pouco o padráo de movimentos corporais estereotipados, repetitivos, que vinha apresentando e produzindo gestos significados por ela, os quais interferem em suas açôes e movimentos. Na medida em que vai identificando que tipo de cançóes e quais movimentos atraem mais a atençáo da criança, Rafaela vai se guiando por eles para manter a interação.

No diálogo corporal estabelecido entre os dois, uma "posição responsiva" de cada um deles permite manter a interação e produzir sentidos sobre o que vivenciam, mesmo sem a reciprocidade verbal.

Tratando da interação verbal, Bakhtin (1992) destaca o enunciado - unidade da língua que veicula/produz sentidos situados num dado tempo e espaço. Os enunciados são sempre dirigidos a alguém e respondem a outros enunciados formulados anteriormente. Assim, cada enunciado de um locutor, em um dos turnos do diálogo, cada réplica, "[...] por mais breve e fragmentária que seja, possui um acabamento específico que expressa a posição do locutor, sendo possível responder, sendo possível tomar, com relaçáo a essa réplica, uma posição responsiva" (BAKHTIN, 1992, p. 294, grifos do autor).

Tomar a noção de "posição responsiva" no processo dialógico nos parece interessante para abordar os processos interativos com sujeitos com comprometimento na linguagem e na comunicaçáo, como costuma ocorrer com crianças com autismo, auxiliando-nos a compreender processos de interlocução mesmo onde a produção verbal é exígua ou unilateral e o diálogo corporal domina.

Essa noção pode auxiliar inclusive na compreensão de processos interlocutivos criados em momentos diferenciados. Bakhtin ressalta que, no fluxo da interação verbal, os enunciados produzidos pelos sujeitos nutrem-se de outros enunciados, que podem ser oriundos de processos dialógicos configurados em tempos e espaços distintos. $\mathrm{Na}$ sessão lúdica que sucedeu à que o evento das cantigas ocorreu, identificamos outros episódios que parecem envolver uma "posição responsiva" a esse evento: 
Murilo está na brinquedoteca. Uma estagiária pega em suas mãos e começa a balançá-las. Ele demonstra gostar dessa atividade. Quando ela solta suas máos, uma das pesquisadoras estende as mãos para ele e seu gesto é acolhido por ele. A pesquisadora começa a rodar com Murilo, cantando a cançấo "Caranguejo peixe é”, enquanto ele balança os braços e a cabeça, demonstrando satisfação com a atividade. Quando canta "Caranguejo peixe é", ela se abaixa, mas Murilo apenas observa. Pouco tempo depois, a pesquisadora repete a mesma brincadeira com ele por mais duas vezes consecutivas. Na última vez, quando ela canta "Roda, roda, roda caranguejo peixe é" e se abaixa, Murilo segue seu movimento: abaixa-se junto com ela, olha para ela e sorri.

Nesse episódio, identificamos um momento significativo de interação e de compartilhamento de uma atividade lúdica entre Murilo e a pesquisadora. Ambos se envolvem em uma brincadeira de roda por três vezes. Enquanto brinca, ele balança os braços e a cabeça e tem uma expressão de contentamento na face.

A cantiga de roda que Murilo apreciou na sessão anterior parece ter sido o que o motivou a interagir com um adulto que, embora estivesse sempre na brinquedoteca, não se relacionava muito diretamente com ele. $\mathrm{O}$ diálogo corporal e expressivo que se estabelece entre eles de certa forma tem como referência o que foi vivenciado na sessão anterior. A iniciativa da pesquisadora de propor a brincadeira com a cantiga é uma resposta aos movimentos dele na sessão anterior, interpretados por ela como prazerosos diante da música. A acolhida de Murilo à brincadeira também pode ser uma resposta à canção e movimentos de Rafaela no penúltimo encontro.

No diálogo corporal e expressivo que se estabelece entre Murilo e a pesquisadora, constatamos que ele imita seu gesto de se abaixar, depois de observá-la três vezes fazendo isso ao final da música. Nesse contexto, apoiando-nos em Bakhtin (1986, 1992), podemos aventar a possibilidade de compartilhamento de sentidos nos movimentos executados pela pesquisadora e por Murilo. Tendo como referência os apontamentos de Vigotski (1979; 2000), parece ser pertinente, ainda, anunciar a emergência de processos de domínio do próprio movimento por meio da apropriação do significado do gesto do outro. Ao abordar o processo de internalizaçáo da linguagem, o autor chama a atenção para a função de comando que a palavra tem na relação da criança consigo própria, colocando em destaque o papel regulador da linguagem. Em crianças que raramente verbalizam, parece pertinente pensar o gesto como uma via alternativa no processo de autorregulação, na medida em que ele pode assumir $o$ status de signo na relação com o outro e consigo próprio.

\section{Considerações finais}

A análise dos processos de interação e de interlocução entre uma criança com autismo e os adultos durante atividades lúdicas na brinquedoteca evidencia as possibilidades de interação, de diálogo e de produção de sentidos, mesmo diante da ausência de verbalização por parte dela. No lugar da palavra, produzem-se o olhar, o movimento, as manifestações expressivas, a aproximação física e o distanciamento do outro, que são significados pelo adulto, sujeito que domina a palavra. $\mathrm{Na}$ medida em 
que as açóes, as manifestaçóes expressivas e os movimentos são interpretados pelo outro e tomados como referência para a condução da interaçáo, uma dinâmica dialógica potencializadora de processos psíquicos emergentes na criança pode se estabelecer.

Olhar para a criança com autismo como um sujeito em condiçôes de produzir sentidos, de se posicionar de forma ativa e responsiva nos processos interativos e buscar compreender suas formas peculiares de participar de uma situação de interlocução, é fundamental para que se possam desenvolver práticas pedagógicas que permitam avanços significativos em seu desenvolvimento. Trata-se, portanto, de compreender a criança com autismo como um ser de linguagem, constituindo-se na relação com o outro por meio da linguagem, ainda que não verbalize ou fale muito pouco.

Este estudo traz contribuiçóes para abordar práticas educativas orientadas para a criança com autismo na educação infantil, na medida em que permite compreender modos de ser e possibilidades de expressão dessa criança e discute sobre formas de aproximação, contato e interação com ela. Um aspecto a ser destacado na análise, o qual não foi possível aprofundar neste trabalho, é a possibilidade de emergência de processos de domínio do próprio movimento pela criança com autismo a partir do gesto do outro, tendo como referência os apontamentos de Vigotski acerca da função autorreguladora da linguagem. Considerando as peculiaridades da linguagem de crianças com autismo, esse é um tema relevante para novas pesquisas.

\section{Referências}

ASSOCIAÇÃO DE PSIQUIATRIA AMERICANA. Manual Diagnóstico e Estatístico de Transtornos Mentais (DSM-V). Porto Alegre: Artmed, 2014.

BAKHTIN, M. Marxismo e filosofia da linguagem. São Paulo: Hucitec, 1986. 196 p.

Estética da criaçáo verbal. São Paulo. Martins Fontes, 1992. 419 p.

BARROS, I. B. R. Autismo e linguagem: discussóes à luz da teoria da enunciaçáo. Distúrbios da comunicaçáo. Sáo Paulo, v. 23, n. 2, p. 227-232, 2011. Disponível em: <http://revistas.pucsp.br/index.php/dic/article/ view/8284/6161>. Acesso em: 3 mar. 2016.

BENVENISTE, E. Problemas de linguística geral. São Paulo: Companhia Editora Nacional, Editora da Universidade de São Paulo, 1976. 386 p.

BOSA, C. Autismo: atuais interpretaçóes para antigas observaçóes. In: BAPTISTA, C. R.; BOSA, C. (Org.). Autismo e educação: reflexóes e propostas de intervenção. Porto Alegre: Artmed, 2002. p. 21-39.

BRASIL. Lei no 13.146, de 6 de junho de 2015. Institui a Lei Brasileira de Inclusão da Pessoa com Deficiência (Estatuto da Pessoa com Deficiência). Brasília. 2015. Disponível em: <http://www.planalto.gov.br/ccivil_03/_ Ato2015-2018/2015/Lei/L13146.htm>. Acesso em: 1 mar. 2016.

Ministério da Educação e Cultura/Secretaria de Educação Especial. Política Nacional de Educação Especial na perspectiva da educaçáo inclusiva, Brasília, 2008. Disponível em: <http://portal.mec.gov.br/arquivos/pdf/ politicaeducespecial.pdf $>$. Último acesso em: 2 mar. 2016.

Ministério da Educaçāo e Cultura/Secretaria de Educação Básica. Política Nacional de Educaçáo Infantil: pelos direitos das crianças de zero a seis anos à educaçáo. Brasília, 2006. Disponível em: <http://portal.mec. gov.br/seb/arquivos/pdf/pol_inf_eduinf.pdf>. Acesso em: 2 mar. 2016.

FAVORETTO, N. C.; LAMÔNICA, D. A. C. Conhecimentos e necessidades dos professores em relaçâo aos transtornos do espectro autístico. Revista Brasileira de Educaçáa Especial, v. 20, n. 1, p. 103-116, 2014. Disponível em: <http://www.scielo.br/pdf/rbee/v20n1/a08v20n1.pdf>. Acesso em: 3 jan. 2018.

LEMOS, E. L. M. D.; SALOMÃO, N. M. R.; AGRIPINO-RAMOS, C. S. Inclusão de crianças autistas: um estudo sobre interaçóes sociais no contexto escolar. Revista Brasileira de Educaçáo Especial, Marília, v. 20, n. 1, p. 117-130, jan./mar. 2014. 
ORGANIZAÇÃO MUNDIAL DA SAÚDE. Classificação Estatística Internacional de Doenças e Problemas Relacionados à Saúde: Capítulo V: Transtornos mentais e comportamentais (F00-F99). 1993. Disponível em: <http://www.datasus.gov.br/cid10/V2008/cid10.htm>. Acesso em: 4 jan. 2018.

PINO, A. S. A psicologia concreta de Vigotski: implicaçóes para a educaçáo. In: PLACO, V. M. N. S. (Org.). Psicologia e educação: revendo contribuiçôes. São Paulo: Educ, 2000.

SAMPAIO, M; MIURA, R. K. K. Concepçóes de professores sobre pessoas com espectro do autismo. Revista Diálogos e Perspectivas em Educação Especial, v. 2, n, 2, p. 145-160, 2015. Disponível em: <http:// www2.marilia.unesp.br/revistas/index.php/dialogoseperspectivas/article/view/5762/3943>. Acesso em: 4 jan. 2018.

SANTOS, M. A.; SANTOS, M. F. S. Representaçóes sociais de professores sobre o autismo infantil. Psicologia \& Sociedade, v. 23, n. 3, p. 364-372, 2012.

SIEGEL, B. O mundo da criança com autismo: compreender e tratar perturbaçóes do espectro do autismo. Porto: Porto Editora, 2008. 432 p.

SCHMIDT, C. et al. Inclusão escolar e autismo: uma análise da percepçáo docente e práticas pedagógicas. Psicologia: Teoria e Prática, v. 17, n. 3, p. 222-235, 2016. Disponível em: <http://pepsic.bvsalud.org/pdf/ptp/ v18n1/17.pdf>. Acesso em: 5 jan. 2018.

VASQUES, C. K.; BAPTISTA, C. R. Transtornos globais do desenvolvimento e escolarizaçáo: o conhecimento em perspectiva. Educação e Realidade, v. 39, n. 3, p. 665-685, 2014. Disponível em: <http://www. scielo.br/pdf/edreal/v39n3/v39n3a03.pdf>. Acesso em: 4 jan. 2018.

VASQUES, C. K. Formas de conhecer em educaçáo especial: o diagnóstico como escudo e lista. Revista de Educação, PUC-Campinas, v. 20, n. 1, p. 51-59, 2015. Disponível em: <https://seer.sis.puc-campinas.edu.br/ seer/index.php/reveducacao/article/view/2943/1972>. Acesso em: 3 jan. 2018.

VIGOTSKI, L. S. "Manuscrito de 1929”. Educaçáo e Sociedade, Revista Quadrimestral de Ciência da Educaçáo/Centro de Estudos Educaçáo e Sociedade, Cedes, n. 71, p. 21-44, 2000.

VIGOTSKI, L. S. Fundamentos de defectología. In: VIGOTSKI, L. S. Obras completas. Cuba: Pueblo y Educación, 1997. t. 5.

VYGOTSKI, L. S. Obras escogidas: problemas del desarrollo de la psique. Madri: Visor. 1983, v. 3. 383 p.

VYGOTSKY, L. S. Pensamento e linguagem. Lisboa: Antídoto, 1979. 209 p.n. 48, p. 27-40, 2014.

\section{Notas}

${ }^{1}$ Manual Diagnóstico e Estatístico de Transtornos Mentais (DSM-V), da Associaçấo Psiquiátrica Americana (2014), e Classificaçáo Estatística Internacional de Doenças e Problemas Relacionados à Saúde (CID-10), da Organização Mundial da Saúde (1993).

\section{Correspondência}

Ivone Martins Oliveira - Universidade Federal do Espírito Santo - Av. Fernando Ferrari, 514 - Goiabeiras, CEP:29075-073. Vitória, Espírito Santo, Brasil.

E-mail: ivone.mo@terra.com.br - sonia.victor@hotmail.com

Recebido em 27 de setembro de 2017

Aprovado em 14 de fevereiro de 2018

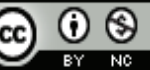

This work is licensed under a Creative Commons Attribution-NonCommercial 4.0 International (CC BY-NC 4.0) 
